\title{
GEOEDUCAÇÃO: PRINCÍPIOS TEÓRICOS E BASES LEGAIS
}

\author{
Marcelo Martins de Moura-Fé ${ }^{(a)}$, Raquel Landim Nascimento ${ }^{(b)}$, Luana do Nascimento Soares ${ }^{(c)}$ \\ (a) Geógrafo. Doutor em Geografia (UFC). Professor do Departamento de Geociências, Pesquisador do NIGEP - \\ Núcleo de Estudos Integrados em Geomorfologia, Geodiversidade e Patrimônio, Universidade Regional do Cariri - \\ URCA, E-mail: marcelo.mourafe@urca.br \\ (b) Graduanda em Geografia. Bolsista de Iniciação Científica - FUNCAP. Pesquisadora do NIGEP - Núcleo de \\ Estudos Integrados em Geomorfologia, Geodiversidade e Patrimônio, Departamento de Geociências, Universidade \\ Regional do Cariri - URCA. Email: raquellandimnasc123@gmail.com \\ (c) Graduanda em Geografia. Bolsista de Iniciação Científica - FUNCAP. Pesquisadora do NIGEP - Núcleo de \\ Estudos Integrados em Geomorfologia, Geodiversidade e Patrimônio, Departamento de Geociências, Universidade \\ Regional do Cariri - URCA. Email: luanasoares760@gmail.com
}

\section{Eixo: GEODIVERSIDADE, GEOARQUEOLOGIA E PATRIMÔNIO NATURAL}

\begin{abstract}
Resumo
Considerando a importância e a amplitude de tudo o que envolve a geodiversidade, incluindo a diversidade litológica, o estudo dos fósseis, a água enquanto recurso limitado e vital à vida, o relevo, os solos e suas condições e implicações para uso e ocupação por parte da sociedade, e, sobremaneira, os registros da história do planeta impressos neste segmento do patrimônio natural; sua valorização e preservação são necessidades inquestionáveis. Por sua vez, entendendo a Educação Ambiental (EA) como uma forma concreta, em suas mais diversas formas de inserção social, para alcançar tais objetivos, propomos o desenvolvimento de uma EA a ser aplicada na geoconservação do patrimônio natural, sobretudo da geodiversidade, a Geoeducação, que deve ser tratada, conforme Moura-Fé et al (2016), fomentada e desenvolvida nos âmbitos formais e/ou não formais do ensino. Aqui, apresentamos e discutimos propostas de princípios teóricos e das bases legais dessa Geoeducação.
\end{abstract}

Palavras chave: Geodiversidade, Geoconservação, Educação Ambiental, Geossítios Araripe

\section{Introdução}

Conceitualmente, a geodiversidade é o resultado da interação de diversos fatores, como as rochas, o clima, os seres vivos, entre outros, possibilitando o aparecimento de paisagens distintas em todo o mundo (BRILHA, 2005), integrando a diversidade geológica (rochas, minerais e fósseis), geomorfológica (formas de relevo) e pedológica (solos), além dos processos que lhes originaram (BÉTARD et al., 2011) e lhes modelam de forma dinâmica e integrada atualmente (MOURA-FÉ, 2015a).

Enquanto testemunha científica dos acontecimentos que marcaram a história evolutiva da Terra, a geodiversidade deve ser conservada como parte fundamental do patrimônio natural e utilizada, sobretudo, para fins científicos, didáticos, culturais e geoturísticos (GODOY et al., 2013), na forma de sítios naturais, os geossítios, com base nos seus 7 (sete) valores fundamentais: intrínseco, cultural, estético, econômico, funcional, científico e didático (MOCHIUTTI et al., 2012). 
Os valores científico e didático talvez sejam os valores mais preciosos atribuídos à geodiversidade, ao passo que a investigação de certos aspectos do meio abiótico permitem delinear a longa história da Terra, desenhar os cenários futuros de uma região, por exemplo, e prevenir-se diante de situações de risco (MOCHIUTTI et al., 2012), dentre outras inúmeras possibilidades de aplicação.

Todavia, por conta do valor econômico, sobretudo, muitas são as ameaças à geodiversidade, onde a sociedade se apresenta como o principal agente modificador e degradador (GRAY, 2005). Na tentativa de reverter esse quadro de vulnerabilidade têm sido criadas estratégias visando à conservação da geodiversidade ou geoconservação, "um ramo de atividade científica que tem como objetivo a caracterização, conservação e gestão do patrimônio geológico e processos naturais associados" (BRILHA, 2005, p. 51), mas que pode ser ampliado e aplicado para a geodiversidade como um todo: geologia, geomorfologia e pedologia (BÉTARD et al., 2011; MOURA-FÉ, 2015a).

Dentro do conjunto de atividades geoconservacionistas destacam-se duas: o geoturismo e a geoeducação (MOURA-FÉ, 2016), onde o primeiro ramo se apresenta mais amplamente discutido, embora ainda não suficientemente conhecido; e o segundo ramo está em processo de construção teórica e aplicada.

O geoturismo pode ser entendido como a atividade turística com conotação geocientífica, que propõe a visita organizada e orientada a locais que testemunham uma fase do passado ou da história de origem e evolução do planeta, que se notabilizam como uma herança coletiva e que devem ser preservados para as gerações futuras. Neste contexto, se inclui o conhecimento científico sobre a gênese da paisagem, os processos envolvidos e os testemunhos registrados em rochas, relevos e solos (SILVA e PERINOTTO, 2007; VIEIRA e CUNHA, 2004).

Num quadro mais amplo e integrado, vale frisar, os conceitos de geodiversidade e geoconservação, juntamente com o geoturismo, formam o trinômio fundamental para a divulgação, valorização e conservação do patrimônio natural (BENTO e RODRIGUES, 2010) e seus geossítios, os quais se configuram como um elo bem estruturado entre esses conceitos: por serem os locais de ocorrência de significativa geodiversidade, por se configurarem como formas de geoconservação e como locais ideais para o desenvolvimento da atividade do geoturismo (MOURA-FÉ, 2015b).

Por sua vez, considerando a importância da geodiversidade e a ampla possibilidade de inserção social da educação ambiental, Moura-Fé et al. (2016) propõem o estabelecimento e o desenvolvimento do conceito científico da geoeducação, como a segunda estratégia geoconservacionista, sendo entendida como um ramo específico da educação ambiental a ser aplicado na geoconservação e que seja tratado, fomentado e desenvolvido nos âmbitos formais e/ou não formais do ensino. 
Todavia, como se sabe, essa aplicabilidade, seja em que âmbito for, formal ou não-formal, em meio urbano ou rural, deve ser precedida por um embasamento teórico. No caso da geoeducação, conforme aproximação feita por Moura-Fé et al. (2016), o suporte parece estar na educação ambiental e seu rico arcabouço teórico-aplicado, desenvolvido por diversos pesquisadores nas últimas décadas e com bases legais já estabelecidas, elementos norteadores que podem ser aplicados na geoconservação.

Desta forma, o objetivo principal deste trabalho é contribuir com o desenvolvimento conceitual da geoeducação, a partir da apresentação e análise dos princípios teóricos e das bases legais pertinentes à educação ambiental, e que podem ser direcionados para a conservação da geodiversidade.

\section{Materiais e Métodos}

A natureza da pesquisa fundamentou-se em uma abordagem de cunho qualitativo que, de acordo com Gil (1996), visa a compreensão ou interpretação de processos de forma complexa e contextualizada e se caracteriza como um plano aberto e flexível. Quanto aos fins esta investigação se caracterizou como descritiva.

No tocante às técnicas de pesquisa, os procedimentos desenvolvidos foram baseados, por um lado, em um criterioso levantamento bibliográfico, com a realização de um estudo sistematizado, investigando materiais publicados em periódicos de revistas científicas estrangeiras e nacionais, em livros e títulos legais vigentes no Brasil e no estado do Ceará, com levantamento dos principais referenciais teóricos e metodológicos pertinentes ao objetivo proposto aqui, com ênfase nos elementos da educação ambiental direcionáveis e aplicáveis à geoconservação.

\section{Princípios Teóricos}

O objetivo geral da educação ambiental, conforme Melo (2007), é formar cidadãs e cidadãos ativos que saibam identificar os problemas e participar efetivamente de sua solução e prevenção, os quais possam ajudar a conservar o nosso patrimônio comum.

Com essa importante missão, a educação ambiental (EA) deve estar presente em todos os espaços de convivência e, principalmente, naqueles que propõe contribuir para a educação das cidadãs e dos cidadãos, assim, além das escolas, ela pode ser feita nas universidades, em cursos profissionalizantes, nas nossas ruas e casas, associações de bairro, locais de trabalho, sindicatos, comunidades religiosas, bem como em locais de lazer como clubes e entidades recreativas, praças, praias, parques, reservas ecológicas (MELO, 2007), nas unidades de conservação e nos geossítios também. 
Como isso pode se dar? A EA tem, dentre outros objetivos, o de elaborar propostas pelas quais a sociedade possa manter uma relação com o meio ambiente (entendido como a natureza em harmonia), sustentabilidade e a igualdade social, entendendo que um ambiente harmonizado proporciona uma melhor qualidade de vida e o melhor meio de conscientização e prática da preservação parece se dar por meio da educação ambiental, ao sensibilizar e aumentar a percepção dos indivíduos para que se tornem mais responsáveis na construção de um modo de vida com mais qualidade (PESSOA e BRAGA 2010).

A EA, entendida assim, se apresenta como um processo educativo articulado, com a sustentabilidade no centro das atenções, por meio do qual se estabeleceria uma relação de encontro com o bem comum, ou seja, ao mesmo tempo em que a educação permitiria o conhecimento, sendo também instrumento de transformação e mudança na forma de pensar, propõe-se ainda a participação ativa da população, proporcionando a construção e introspecção de valores como a ética, sustentabilidade, identidade cultural e diversidade, mobilização, participação e práticas interdisciplinares (SORRETINO, 1998).

Pode-se aferir acerca do que foi dito até aqui, que a EA trata-se, sobretudo, de um ato político que busca promover uma mudança social, instituindo novos valores e promovendo a conscientização e o desenvolvimento de estudos e técnicas em prol da preservação ambiental, bem estar e melhoria nas relações entre os seres humanos e o meio ambiente (CARVALHO, 2006).

Assim, Jacobi (2003) propõe uma EA crítica e inovadora, que possa transformar a realidade social, sendo um processo de permanente aprendizagem, objetivando valorizar todas as formas de conhecimentos e possibilitando uma visão consciente sobre o valor da natureza, do que entendemos aqui como patrimônio, incluindo a geodiversidade.

A EA, para Dias (2004), é um processo permanente no qual os individuos e a comunidade devem tomar consciência do seu meio ambiente e adquirem conhecimentos, valores, habilidades, experiências e determinação, por fim, que os tornem aptos a gir e resolver problemas ambientais, sejam eles postos no presente, sejam eles prognosticados para o futuro.

Desta forma, a EA, com a missão de formar cidadãs e cidadãos ativos; a possibilidade concreta de se poder estar presente em todos os espaços de convivência, incluindo os geossítios e as comunidades circunvizinhas; considerando o objetivo historicamente construído de elaborar propostas pelas quais a sociedade possa manter uma relação com o meio ambiente, objetivo complexo, mas bem-sucedido em diversos estudos de caso espalhados no país; se apresentando como um processo educativo articulado, interdisciplinar, que busca promover uma mudança social, de forma eminentemente crítica e inovadora, apresenta todos os elementos teóricos para o desenvolvimento da geoeducação. 
Tais elementos norteadores, longe de esgotarem o cabedal de possibilidades, nos dão os elmentos característicos da EA, conforme Dias (2004, p. 523):

- Enfoque orientado à solução de problemas concretos da comunidade;

- Enfoque interdisciplinar;

- Participação da Comunidade;

- Caráter permanente, orientado para o futuro.

Adotando tais princípios teóricos, por exemplo, a geoeducação a ser aplicada no nível não formal, ou seja, fora do ambiente escolar formal, pode ser desenvolvida através de programas direcionados para a divulgação e fomento da geoconservação considerando as realidades concretas vivenciadas por cada comunidade, buscando incessantemente a participação das pessoas que as vivenciam e, conforme apontado por Moura-Fé et al. (2016), embora fora do contexto pedagógico do ensino formal, sem perder o caráter educativo de informar e formar.

Aliás, é válido apontar que essa geoeducação não formal tem sua importância mais que justificada pela ampla possibilidade de aplicabilidade em qualquer local dotado de geodiversidade, desvinculada do possível enrijecimento associado aos currículos e parâmetros escolares, sendo acessível à iniciativa e criatividade de seus proponentes, os quais podem realizar ações e práticas educativas voltadas à sensibilização das comunidades, envolvendo flexibilidade de métodos e de conteúdos e um público alvo variável em suas características (MOURA-FÉ et al., 2016).

Por outro lado, deve-se frisar a importância da estratégia de divulgação e sensibilização da geoconservação também junto ao público estudantil no ensino formal, a qual se dá pelo fato desse segmento da sociedade ser mais aberto a esse tipo de iniciativa e ter uma capacidade de interiorização de mensagens de caráter ambiental mais acentuada. Vieira e Cunha (2004) também apontam para a importância de se abordar os conteúdos pertinentes ao patrimônio natural nos níveis mais básicos da educação, integrando-os aos currículos disciplinares.

De maneira geral, a inserção da EA no processo educativo brasileiro é importante, mas passa pela necessidade de diversas mudanças, dentre elas, no ensino superior, formador dos formadores, sobretudo nos cursos de licenciatura, que ainda encontram-se sustentados na fragmentação do conhecimento e ainda ancorados essencialmente na disciplinaridade, conforme Oliveira (2006). Além disso, é preciso vontade política dos governantes para colocar a EA nas diretrizes orçamentárias e realizar as políticas públicas voltadas para sua ampla e concreta implementação no país. 


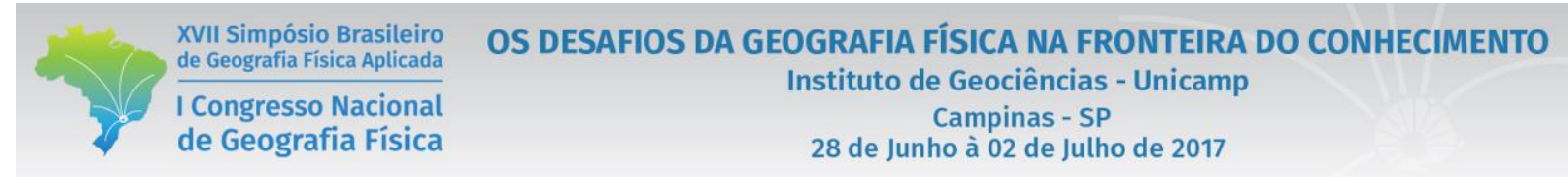

Tecendo uma linha da relação (que será necessária) entre geoeducação e geoturismo, Klein et al., (2011) apontam que a EA já envolve ações e práticas educativas voltadas à sensibilização da coletividade sobre as questões ambientais e à sua organização e participação na defesa da qualidade do meio ambiente consorciada com a prática do ecoturismo e geoturismo, segmentos importantes do turismo sustentável. Por exemplo, com a prática de campo orientada cientificamente é possível vivenciar a inter-relação das condições físicas do local, as formas de relevo e a ocupação da sociedade instituída em um determinado ambiente (KLEYN et al., 2011).

Contudo, diversas outras formas de aplicabilidade transitando entre o geoturismo e a geoeducação já são bem desenvolvidas no contexto da EA, tais como apontados por Almeida e Porto Junior (2012); Hissa e Oliveira (2004); Klein et al. (2011); Kroeff e Verdum (2011); Lopes et al. (2011); Moreira (2012); Russ e Nolasco (2012); Sanches (2011); Vieira e Cunha (2004):

1. O estabelecimento de centros de interpretação ambiental, preferencialmente em UCs, adequando a infraestrutura ao público estudantil;

2. Elaboração, instalação e uso de painéis interpretativos (Figura 1), de material impresso e de vídeos adequados para cada nível escolar;

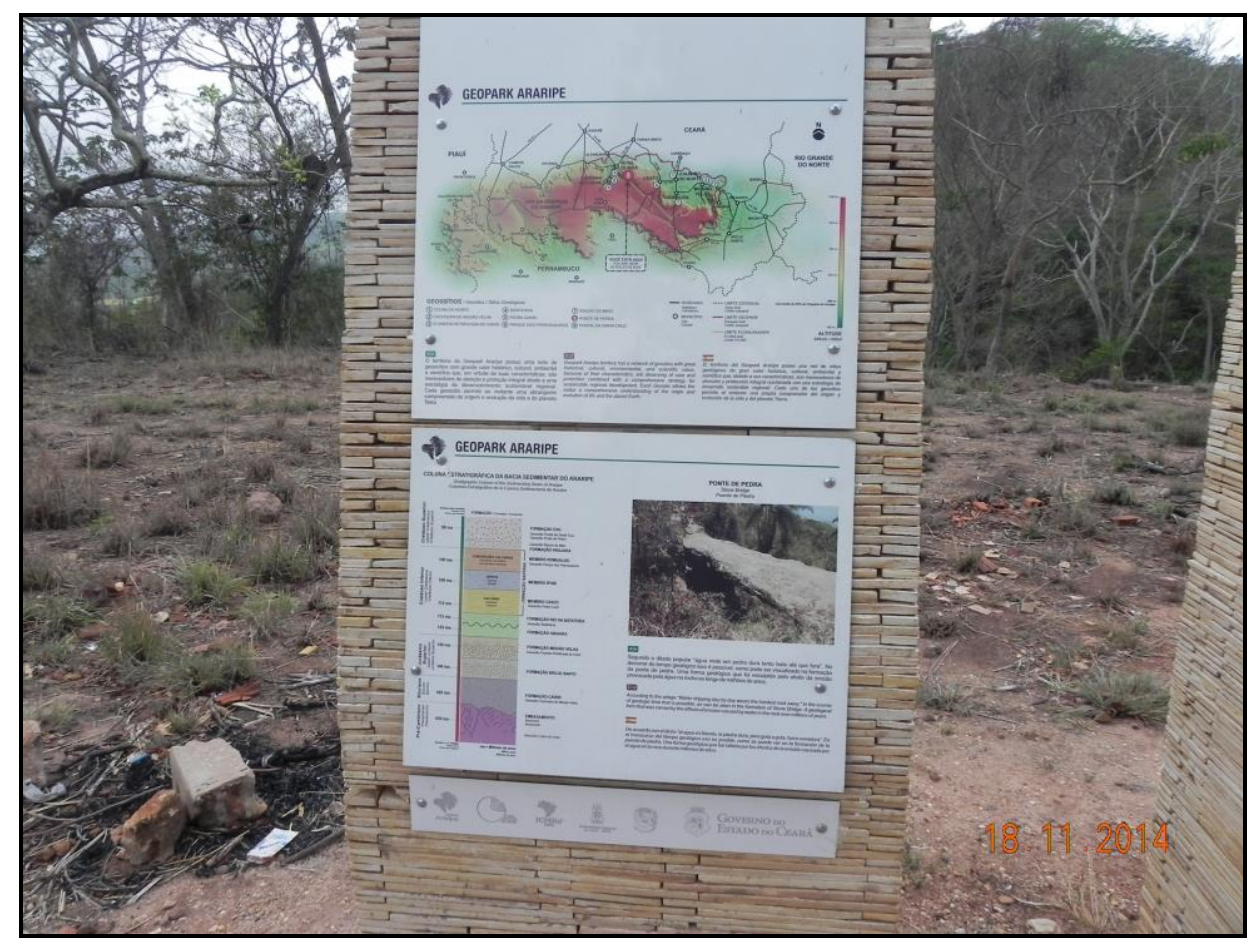

Figura 1 - Painel interpretativo do geossítio Ponte de Pedra, em Nova Olinda-CE - GeoPark Araripe.

Foto: Marcelo Moura Fé, Nov/2014. 
XVII Simpósio Brasileiro

de Geografia Fisica Aplicada

I Congresso Nacional

de Geografia Física
OS DESAFIOS DA GEOGRAFIA FÍSICA NA FRONTEIRA DO CONHECIMENTO

Instituto de Geociências - Unicamp

Campinas - SP

28 de Junho à 02 de Julho de 2017

3. Realização de palestras, jogos e outras atividades lúdicas (como escaladas, por exemplo);

4. Exposições em museus com os mais variados temas;

5. Adoção da prática dos conteúdos de sala em trabalhos de campo, o que pode ser feito em excursões e visitas guiadas, que podem ser apoiadas por técnicos com capacidade adequada e formação científica;

6. Concepção e implementação de trilhas e percursos educativos e turísticos (Figura 2).

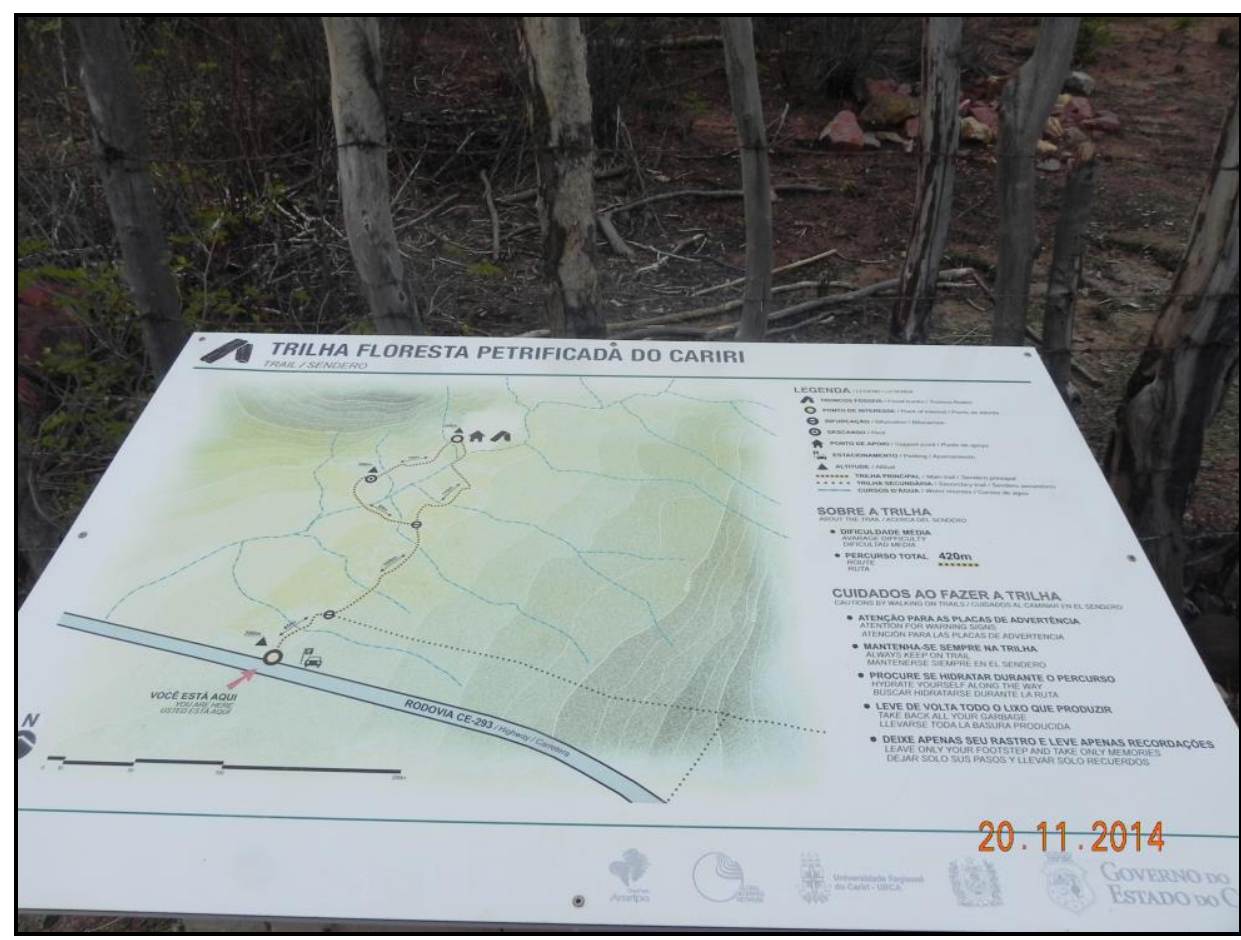

Figura 2 - Painel informativo da trilha do geossítio Floresta Petrificada do Cariri, em Missão Velha-CE GeoPark Araripe. Foto: Marcelo Moura Fé, Nov/2014.

A partir do exercício de práticas educativas desenvolvidas para a geoeducação e considerando sempre as motivações fundamentais do geoturismo: recreação, lazer e aprendizado, tem-se a possibilidade de valoração e valorização da geodiversidade ao longo prazo, gerando um sentimento de respeito e corresponsabilidade pela manutenção da conservação ambiental (BENTO e RODRIGUES, 2013) nos estudantes e nas comunidades como um todo, o qual, se pensado e aplicado de forma ampla e consistente, pode perdurar por mais tempo ao se inserir no cotidiano das gerações atuais e futuras. 
Os princípios teóricos da EA, para além de sua importância em diversas formas de aplicabilidade, também foram fundamentais na composição das bases legais que hoje sustentam e a norteiam. Essas bases legais serão apresentadas em linhas centrais no ítem a seguir, apontando elementos presentes na legislação vigente que irão fundamentar a teorização e a aplicabilidade da EA na geoconservação, ou geoeducação.

\section{Bases Legais}

Neste ítem iremos nos ater basicamente à apresentação e disucssão de dois diplomas legais, os quais instituem o Plano Nacional de Educação Ambiental (PNEA) e o Plano Estadual de Educação Ambiental do estado do Ceará (PEACE); onde o primeiro se notabiliza com o principal referencial legal para a EA em todo o país, e o segundo precisa ser mais divulgado, debatido e implantado no contexto territorial onde iremos nos embasar para propor a aplicabilidade da geoeducação: os seis municípios da região sul cearense que conformam o GeoPark Araripe. Mas isso será assunto para outro momento.

Conforme Dias (2004), o Brasil é o único país da América Latina que tem uma política nacional específica para a EA. Conforme a lei federal $n^{\circ}$ 9.795/1999:

Entende-se por educação ambiental os processos por meio dos quais o indivíduo e a coletividade constroem valores sociais, conhecimentos, habilidades, atitudes e competências voltadas para a conservação do meio ambiente, bem de uso comum do povo, essencial à sadia qualidade de vida e sua sustentabilidade (BRASIL, 1999, art. $1^{\circ}$ ).

Nessa perspectiva, a lei reconhece a EA como um componente essencial e permanente em todo processo educativo, formal e/ou não formal, como orientam, aliás, os artigos 205 e 225 da Constituição Federal de 1988 (SILVA, 2003).

Outro fator básico a ser considerado, presente no art. $2^{\circ}$ é que a EA é um componente essencial e permanente da educação nacional e que deve estar presente, de forma articulada, em todos os níveis e modalidades do processo educativo, seja caráter formal ou não-formal, como já apontado em Moura-Fé et al. (2016). Além disso, qualquer proposição teórica para a geoducação deve considerar os princípios básicos $\left(\operatorname{art.~} 4^{\circ}\right)$ e os objetivos fundamentais $\left(\operatorname{art.~} 5^{\circ}\right)$ da educação ambiental.

Por sua vez, em termos de desenvolvimento de aplicabilidades, o art. $8^{\circ}$ aponta elementos importantes, a saber:

Art. $8^{\circ}$ As atividades vinculadas à Política Nacional de Educação Ambiental devem ser desenvolvidas na educação em geral e na educação escolar, por meio das seguintes linhas de atuação inter-relacionadas: 
I - capacitação de recursos humanos;

II - desenvolvimento de estudos, pesquisas e experimentações;

III - produção e divulgação de material educativo;

IV - acompanhamento e avaliação (Grifo nosso).

O PNEA apresenta todos os elementos básicos para se desenvolver a geoeducação, seja enquanto teoria seja enquanto conjunto de ações e estratégias aplicadas, desde que se observe a vinculação das suas diretrizes com o arcabouço teórico já desenvolvido em torno da geodiversidade, da geoconservação e do geoturismo. Estes são os próximos passos da pesquisa em desenvolvimento.

Com base nesta lei federal, também foi desenvolvido o PEACE, instituído através da lei estadual $\mathrm{n}^{\circ}$ 14.892, de 31 de março de 2011, que dispõe sobre a educação ambiental, institui a política estadual de educação ambiental (CEARÁ, 2011) e que conceitua, em seu art. 1ª a EA como um "rocesso contínuo de formação visando o desenvolvimento de uma consciência crítica sobre relações históricas, entre a sociedade e a natureza, capaz de promover a transformação de hábitos, atitudes e valores necessários à sustentabilidade ambiental para efeito desta Lei”.

Em termos teóricos o PEACE apresenta os princípios (art. $2^{\circ}$ ) e os objetivos (art. $3^{\circ}$ ) que devem ser aplicados no contexto cearense, os quais serão analisados e tratados de forma mais enfática em um outro momento. Por sua vez, no que tange à proposição de aplicabilidades, o PEACE tem em seu artigo $5^{\circ}$ um importante elemento balisador.

Art. $5^{\circ}$ As atividades vinculadas à Política Estadual de Educação Ambiental, no âmbito das entidades citadas no artigo anterior, devem ser desenvolvidas com as seguintes linhas de atuação:

I - capacitação em Educação Ambiental;

II - Educação Ambiental nas áreas formal e não-formal;

III - fomento de mecanismos de articulação e mobilização da comunidade para a

Educação Ambiental;

IV - Educação Ambiental e mecanismos de gestão dos recursos naturais;

V - comunicação e arte na Educação Ambiental;

VI - fomento de estudos e pesquisas em Educação Ambiental;

VII - produção e divulgação de material educativo;

VIII - articulação intra e interinstitucional; 
IX - criação da Rede Cearense de Educação Ambiental - RECEBA;

X - acompanhamento e avaliação permanentes da Educação Ambiental no Estado do

Ceará.

Por fim, vale destacar, do contrário que acontece com certa regularidade nos casos de elaboração de uma lei estadual a partir de uma lei federal, onde há uma certa repetição do escopo, para não mencionar verdadeiras cópias, o PEACE avança no sentido da complementaridade em relação ao PNEA, não só neste art. $5^{\circ}$, mas em outros artigos que versam sobre o ensino formal e não-formal (art. $6^{\circ}, 7^{\circ}$ e $8^{\circ}$ ), o que só enriquece e dá mais elementos para a construção da geoeducação.

\section{Considerações Finais}

Conforme visto, considerando a importância e a amplitude de tudo o que envolve a geodiversidade e seus segmentos (geoconservação e o geoturismo), incluindo a diversidade litológica, o estudo dos fósseis, a água enquanto recurso limitado e vital à vida, o relevo, os solos e suas condições e implicações para uso e ocupação por parte da sociedade, e, sobremaneira, os registros da história do planeta impressos neste segmento do patrimônio natural, sua valorização e preservação são necessidades inquestionáveis.

Por sua vez, entendendo a educação ambiental como uma forma concreta, em suas mais diversas formas de inserção social, ao ser dotada de elementos teóricos importantes para alcançar tais objetivos de geoconservação, muitos deles já consolidados na literatura científica e na legislação vigente, com destaque para o PNEA (em termos de Brasil) e o PEACE (em termos de Ceará), propomos o desenvolvimento de uma EA a ser aplicada na geoconservação, a geoeducação.

Assim, apresentamos aqui princípios teóricos importantes e duas bases legais fundamentais para o desenvolvimento de um arcabouço teórico para a geoeducação. Essa base teórica deve, dentre outras possibilidades, embasar a elaboração de um conjunto de ações e estratégias de aplicação deste ramo da EA nos níveis formais e não formais do ensino, seja em meios urbanos ou rurais. Para isso, a contribuição de outros pesquisadores, outros grupos de pesquisa, além do próprio desenvolvimento do projeto de pesquisa ao qual este trabalho está vinculado e apresentando os primeiros resultados, são fundamentais.

\section{Agradecimentos}

Os resultados deste trabalho fazem parte do projeto de pesquisa intitulado: "Geoeducação: contribuição teórica e desenvolvimento da aplicabilidade no GeoPark Araripe", desenvolvido pelos autores deste artigo, o qual é financiado pela Fundação Cearense de Apoio ao Desenvolvimento Científico e 
Tecnológico - FUNCAP, a quem agradecemos pelo apoio concedido através da concessão das duas bolsas de iniciação científica.

\section{REFERÊNCIAS}

ALMEIDA, S. e PORTO JUNIOR, R. Projeto Ciclo das Rochas: um exemplo bem sucedido do uso do patrimônio geológico como estímulo ao aprendizado de ciências naturais. Anuário do Instituto de Geociências - UFRJ (Rio de Janeiro-RJ), v. 35, n.1, p. 28-33, 2012.

BENTO, L. C. M. e RODRIGUES, S. C. Geoturismo em unidades de conservação: uma nova tendência ou uma necessidade real? Revista do Departamento de Geografia, v. 25, p. 77-97, 2013.

O Geoturismo como instrumento em prol da divulgação, valorização e conservação do patrimônio natural abiótico - uma reflexão teórica. Pesquisas em Turismo e Paisagens Cársticas, v. 3, n. 2, p. 55-65, CampinasSP: 2010.

BÉTARD, F.; PEULVAST, J-P. e MAGALHÃES, A. O. Biodiversité, géodiversité et enjeux de leur conservation dans les montagnes humides du Nordeste brésilien. BAGF. Géographies, p. 17-26, 2011.

BRASIL. Casa Civil. Lei Federal $\mathbf{n}^{0}$ 9.795, de 27 de abril de 1999. Dispõe sobre a educação ambiental, institui a Política Nacional de Educação Ambiental e dá outras providências. Poder Executivo. Brasília, 1999.

BRILHA, J. B. R. Patrimônio geológico e geoconservação - a conservação da natureza na sua vertente geológica. Braga: Palimage, 2005. 190 p.

CARVALHO, I. C. M. Educação ambiental: a formação do sujeito ecológico. 2.ed. São Paulo: Cortez, 2006.

CEARÁ. Casa Civil. Lei Estadual no 14.892, de 31 de março de 2011, que dispõe sobre a educação ambiental, institui a política estadual de educação ambiental e dá outras providências. Fortaleza: DOE publicado em 04 de abril de 2011. Série 3, Ano III, n 064. Caderno 1/2.

DIAS, G. F. Educação Ambiental: princípios e práticas. 9 ed. São Paulo: Gaia, 2004.

GIL, A. C. Como elaborar projetos de pesquisa. 3 ed. São Paulo: Atlas, 157 p. 1996.

GODOY, L. H.; SARDINHA, D. S.; BERTINI, R. J.; CONCEIÇÃO, F. T.; DEL ROVERI, C. e MOREIRA, C. A. Potencial Geoparque de Uberaba (MG): geodiversidade e geoconservação. Revista Sociedade \& Natureza, v. 25, n. 2, p. 395-410, 2013.

GRAY, M. Geodiversity and Geoconservation: what, why, and how? Geodiversity e Geoconservation, p. 4-12, 2005.

HISSA, C. E. V. e OLIVEIRA, J. R. O trabalho de campo: reflexões sobre a tradição geográfica. Boletim Goiano de Geografia - UFG (Goiânia-GO), v. 24, n. 1/2, p. 31-41, 2004.

JACOBI, P. Educação Ambiental, Cidadania e Sustentabilidade. Cadernos de Pesquisa, n. 118, 2003.

KLEIN, F. M.; ESCANDOLHERO, J. P. O.; LUCCHESE, N. R.; MERCANTE, M. A. FÁVERO, S. e RODRIGUES, S. C. Educação ambiental e o ecoturismo na Serra da Bodoquena em Mato Grosso do Sul. Revista Sociedade \& Natureza, v. 23, n. 2, p. 311-321, 2011.

KROEFF, L. L. e VERDUM, R. Identificação de áreas potenciais ao mapeamento de trilhas ecoturísticas na propriedade do ecoparque, em Canela/RS. Revista Brasileira de Geomorfologia - UGB, v. 12, n. 3, p. 131-136, 2011.

LOPES, L. S. O.; ARAÚJO, J. L. e CASTRO, A. J. F. Geoturismo: Estratégia de geoconservação e desenvolvimento local. Revista Caderno de Geografia, v. 21, n. 35, 2011.

MELO, G. P. Educação ambiental para professores e outros agentes multiplicadores. João Pessoa: Superintendência do IBAMA na Paraíba, 2007. 
MOCHIUTTI, N. F.; GUIMARÃES, G. B.; MOREIRA, J. C.; LIMA, F. F. e FREITAS, F. I. Os valores da geodiversidade: geossítios do Geopark Araripe/CE. Anuário do Instituto de Geociências, v. 35, n. 1, p. 173-189, 2012.

MOREIRA, J. C. Interpretação ambiental, aspectos geológicos e geomorfológicos. Boletim de Geografia, v. 30, n. 2, p. 87-98, 2012.

MOURA-FÉ, M. M. GeoPark Araripe e a geodiversidade do sul do Estado do Ceará, Brasil. Revista de Geociências do Nordeste., v. 2, n. 1, p.28-37, 2016.

Evolução Geomorfológica da Ibiapaba setentrional, Ceará: Gênese, Modelagem e Conservação. 307 f. Tese (Doutorado em Geografia). Centro de Ciências, Universidade Federal do Ceará, Fortaleza, 2015a.

. Geoturismo: uma proposta de turismo sustentável e conservacionista para a Região Nordeste do Brasil. Sociedade \& Natureza, v. 27, n. 1, p. 53-66, Uberlândia-MG: 2015b.

MOURA-FÉ, M. M.; PINHEIRO, M. V. A.; JACÓ, D. M.; OLIVEIRA, B. A. Geoeducação: a educação ambiental aplicada na geoconservação. In: Educação Ambiental \& Biogeografia. 1 ed. Ituiutaba-SP: Barlavento, 2016, v. II, p. 829-842.

OLIVEIRA, S. F. Educação ambiental: aspectos históricos e perspectivas. Boletim Goiano de Geografia, v. 26, n. 2, p. 151-166, 2006.

PESSOA, G. P e BRAGA, R. B. Educação Ambiental escolar e qualidade de vida: desafios e possibilidades. Revista Eletrônica Mestrado Educação Ambiental, v. 24, p.143, 2010.

RUSS, B. R. e NOLASCO, M. C. Revelando a geodiversidade através da educação ambiental: percepção de estudantes sobre o geossítio Manga do Céu. Anuário do Instituto de Geociências, v. 35, n. 1, p. 271-280, 2012.

SANCHES, F. O. O Trabalho de campo e análise da paisagem: proposta metodológica no Parque Nacional de Itatiaia. Revista Brasileira de Geografia Física, v. 4, p. 857-871, 2011.

SILVA, J. B. Educação Ambiental. In: CLAUDINO-SALES, V. (Org). Ecossistemas Brasileiros: Manejo e Conservação. Fortaleza: Expressão Gráfica e Editora, 2003.

SILVA, J. R. B. e PERINOTTO J. A. J. O Geoturismo na geodiversidade de Paraguaçu Paulista como modelo de geoconservação das estâncias. Revista Global Tourism, v. 3, n. 2, 2007. 40 p.

SORRENTINO, M. De Tbilisi a Tessaloniki, a educação ambiental no Brasil. In: JACOBI, P. et al. (org.). Educação, meio ambiente e cidadania: reflexões e experiências. São Paulo: SMA.1998. p.27-32.

VIEIRA, A. B. e CUNHA, L. Património Geomorfológico: tentativa de sistematização. Actas do III Seminário Latino Americano de Geografia Física, Puerto Vallarta (MEX), 2004. 